\title{
TIME
}

B R I L L

Timing \& Time Perception 6 (2018) 125-153

$\overline{\text { brill.com/time }}$

\section{The Illusory Flow and Passage of Time within Consciousness: A Multidisciplinary Analysis}

\author{
Ronald P. Gruber1, Ryan P. Smith² and Richard A. Block, ${ }^{3}$ * \\ ${ }^{1}$ Stanford University Medical Center, Stanford, CA, USA \\ ${ }^{2}$ Department of Physics, California State University, East Bay, Hayward, CA, USA \\ ${ }^{3}$ Department of Psychology, Montana State University, Bozeman, MT, USA
}

Received 8 May 2017; accepted 9 December 2017

\begin{abstract}
Flow and passage of time puzzles were analyzed by first clarifying their roles in the current multidisciplinary understanding of time in consciousness. All terms (flow, passage, happening, becoming) are carefully defined. Flow and passage are defined differently, the former involving the psychological aspects of time and the latter involving the evolving universe and associated new cerebral events. The concept of the flow of time (FOT) is deconstructed into two levels: (a) a lower level - a perceptual dynamic flux, or happening, or flow of events (not time); and (b) an upper level - a cognitive view of past/present/future in which the observer seems to move from one to the other. With increasing evidence that all perception is a discrete continuity provided by illusory perceptual completion, the lower-level FOT is essentially the result of perceptual completion. The brain conflates the expression flow (passage, for some) of time with experiences of perceptual completion. However, this is an illusory percept. Converging evidence on the upper-level FOT reveals it as a false cognition that has the illusory percept of object persistence as its prerequisite. To research this argument, an experiment that temporarily removes the experience of the lower-level FOT might be conducted. The claustrum of the brain (arguably the center of consciousness) should be intermittently stimulated to create a scenario of discrete observations (involving all the senses) with long interstimulus intervals of nonconsciousness and thereby no perceptual completion. Without perceptual completion, there should be no subjective experience of the lower-level FOT.
\end{abstract}

\section{Keywords}

Object persistence, persistence, discrete perception, flow of time, passage of time, perceptual completion, time consciousness, specious present

* To whom correspondence should be addressed. E-mail: block@montana.edu 
"Until we have a firm understanding of the flow of time, or incontrovertible evidence that it is indeed an illusion, then we will not know who we are."

Davies (2004, p. 278)

\section{Introduction}

\subsection{Consciousness and the Flow of Time}

Andersen and Grush (2009) reviewed the history of time consciousness. James (1890; see Block, 1994) a psychologist, philosopher and trained physician, described the experience of time as a stream of consciousness. It is a series of moments in which each moment that comes into existence and disappears only to be replaced by another. The thoughts and conscious reactions to events that comprise those moments are perceived as a continuous flow. Husserl (see Almang, 2013; Brough, 1991; Zahavi, 2003), a student of physics and mathematics before becoming a philosopher, discussed the same general phenomenon as inner time consciousness, a component of his definition of the flow of time (FOT). Inner time consciousness is an experience of both succession and duration of events, both of which contribute to the specious present. The human brain experiences objects of the world in sequential order. On the other hand, it also experiences time when viewing immobile or fixed objects. This is like James's (1890) stream of consciousness. Blackmore (2002; see Grube, 2014) challenged the concept of stream of consciousness, but not consciousness per se. Much if not most of what we see is a reconstruction (by filling in the incompleteness of what is perceived) that makes a world appearing complete. What we perceive is not as rich in detail as it appears. In addition, consciousness is not necessarily continuous in time. Bergson suggested that the nature of consciousness is "an inner life that is ceaselessly changing an inner world in which one state of consciousness flows into the next"; Barnard, 2010, p. 45). Bergson said that the moments of consciousness are not separate from each other. He said: "there are no snapshots cut off from the rest; there is simply the continuous flow of our awareness" (Barnard, 2010, p. 46). For lack of a better definition of consciousness, many consider awareness (including self-awareness) to be one of the best ways to describe what is meant by consciousness (Nunez, 2010).

The views of Hameroff and Penrose (2003) are consistent with James's view of consciousness as a set of discrete moments (or near instantaneous nows). In their view, consciousness is a sequence of quantum events inside the brain (associated or correlated stochastically with external events, or stimuli) that are, in effect, perceptual moments, which then 'march' in sequence. The percept of a light flash is an example of a perceptual moment resulting from a quantum reduction. In addition, the brain is said to apply the perceptual illusion of continuity to all those moments which is referred to as flow. For Hameroff (2014; see also Hameroff \& Penrose, 2003, 2014; Penrose, 1994; Penrose \& Hameroff, 2011) consciousness 
creates both a sequence and a flow of moments: "Consciousness creates time" (p. 390). Although this is a hotly debatable topic, and not all agree (Grush \& Churchland, 1995). Some of the most respected neuroscientists (e.g., Koch \& Hepp, 2006) acknowledge that there may be a role for quantum mechanics in the process of consciousness.

Regarding the specifics of the flow of time within consciousness, Rickles and Kon (2014) noted that there are two camps: One thinks that there is a genuine flow in the world and another (the non-illusion camp) thinks that there is just a block of events. If flow is said to be an illusion, however, they argued that it "is not enough to simply dismiss the FOT as a mind-dependent illusion" (p. 4). One still needs to know that even if there is a genuine consistency between the mechanisms underlying such illusory features and the physical models of the universe. One needs to know what aspects of flow are illusory. Arstila and Lloyd (2014) also provided an extensive recent review of time, including temporality and subjective time.

\subsubsection{Illusion Camp}

The history of the illusion of time begins with philosophers such as Parmenides, who maintained that physical reality is timeless (see Whitrow, 1980). Following him was Archimedes, who is the prototype of those whose philosophy of physics presupposes the elimination of time - those who believe that temporal flux is not an intrinsic feature of the ultimate basis of things (see Whitrow, 1980). The modern group of illusion camp philosophers and physicists includes people such as McTaggart (2009) and Einstein (best described by Davies, 2002). Einstein's fourdimensional Block Universe Theory is usually depicted as a three-dimensional graph [two of distance $\left(d_{1}\right.$ and $\left.d_{2}\right)$ one of time $(-t)$ ]. His theory, which is widely adopted by physicists, suggests that events are just there individually. One needs no account of motion to connect the events, and according to Einstein the past/ present/future distinction is a "stubborn illusion" (Davies, 2002, 2004; Gruber, 2008). It is an experiential phenomenon in which time (more specifically events) moves past the apparently single observer like a river, hence the term flow of time (FOT).

Exactly what Einstein meant by "illusion" is not known. It is possible that he thought of it in terms of a cognitive error (see Hoerl, 2014) or an actual perceptual illusion involving the senses. Dainton (2011) agreed, suggesting that the FOT is an illusion, and finds that the block universe theory accommodates a philosophical conclusion better than any other.

Most cosmological theories today are, in fact, timeless (for a review see Petkov, 2007) in which time is a derived entity. Based upon the single equation:

$$
\hat{H}(x)|\psi\rangle=0
$$

of Wheeler-DeWitt, from which most fundamental laws can be derived, Barbour's $(1997,2000,2008)$ popular quantum gravitational theory is the easiest to 
explain. He suggested that the universe is filled with what we can call nows, a vast assemblage of configuration spaces. Each now is a point in spacetime and can metaphorically be thought of as a snapshot containing information such as the brain's memories at that instantaneous moment. There is no connection between the snapshots. Each one, upon quantum wave reduction, provides information about the event at that moment and also memories of prior snapshots that provide a direction to the nows (to the succession of snapshots, Barbour et al., 2014). All timeless cosmological theorists argue that psychology and neuroscience regard the FOT between brief events as an illusion.

\subsubsection{Non-illusion Camp}

In philosophy, Aristotle was the forerunner of those who believe that time is fundamental when he insisted that "there are real comings-into-being" (Whitrow, 1980, p. 1). Modern dissenters of the illusion view include Skow (2011) and Maudlin (2007). For a review, see Callender (2010). In physics, Ellis $(2008,2014)$ and Elitzur $(1991,1996)$ suggested that the block universe evolves or grows. The future is not called there, as in the conventional block universe, but instead comes into existence (by way of quantum mechanics) and is said not to be an illusion. It is not an illusion because the experiential phenomenon coincides with physics, as exemplified by the cosmological theory of Smolin (1997, 2013a, b; 2014). Moreover, Smolin adopted the view that time is real and that the laws of physics are not constant: "what is real in our universe is real in a moment of time which is one of a succession of moments" (Smolin, 2013a, p. xiv). Specifically, he said that motion itself is not an illusion. Carroll (2008) said that the arrow of time is real but does not necessarily agree that the universe comes into being moment by moment. Finally, Prosser (2012), who is not part of the non-illusion camp, noted that a few modern cosmologies would agree with the A-theory described by McTaggart (2009), such as the growing (evolving) block universe.

Other non-illusion researchers suggest that there is no such phenomenology of flow or passage. For example, Hoerl $(2013,2014)$ suggested that there is a specific structural aspect of the phenomenology of perceptual experiences of movement and change that can explain how one might come to the belief that such experiences involve a phenomenology of passage. He also added that there is no reason to involve an additional illusory phenomenology of passage. Huggett (2014) referred to the belief as a mistake. Park (1971) considered the past/present/future experience to be a myth, an incorrect thought process as opposed to an error on the part of the senses. Finally, Baron et al. (2015) provided a clear and concise exposition of this non-phenomenology view.

\subsection{Clarification of Terms}

\subsubsection{Flow and Happening}

One of the fundamental causes of the controversies regarding time, inner consciousness, FOT, and passage of time is the failure to clarify or define terms. 
Agreement can be much more forthcoming if that is done first. Price (2011) denoted three components to the FOT: (a) an objective (present) moment, (b) an objective temporal direction (earlier/later phenomenon); and (c) objective dynamism - a dynamic, flux-like character. Flow is a term often used to refer to that flux. It is a perceptual phenomenon, debatably an illusion, but not a cognition. Many theorists, however, have used the term in a totally different manner. Kastner (2015) suggested that flow is the phenomenon of "actualized events receding away from us into the past" (p. 175). Elitzur (1991) used the term passage when referring to the past/present/future phenomenon but on occasion would use the term flow synonymously with it. We too, in the past, have inadvertently conflated those two terms.

The term happening is not common in the literature on the FOT. When it is used, however, it is very telling. For example, attempting to improve the block universe theory by making it an evolving block universe, Ellis (2014) admitted that his theory leaves out what is happening (a human observable or percept). It also leaves out "the way that the continually changing correlations flow smoothly in a continuous ongoing way" (p. 39). His flow (which he occasionally referred to as happening) is like Price's third component of the FOT (a dynamic flux-like character). To simplify, it is best to define flow and happening as the same phenomenal perceptual experience of dynamic action associated with a sequence of multiple events. Finally, we want to be clear that happening, referred to here, is not to be confused with the emotional response of what happens within consciousness, which Damasio (1999) described so well.

\subsubsection{Passage and Becoming}

The term passage is used in a wide variety of ways (Huggett, 2014). Occasionally, it is a psychological term referring to the subjective duration of time (Wearden, 2016). In philosophy, it is commonly used to denote the experiential phenomenon of past/present/future (Ismael, 2016). Similarly, Dicks (2016) referred to it as the experiential phenomenon that the specious present (or now as he also called it) seems to move from the present into the past. For him, the feeling of flow and passage is well represented in the A-theory of time, which involves a moving now. For Dicks, passage is a quale, not an illusion. For Williams (1951), passage is the mere occurrence of events. However, Savitt (2002, p. 157) was quick to ask if passage also involves "the real whooshy, zingy thing that is so salient in our experience," which we call flow. In physics, passage is usually a cosmological term. For example, in his Spacetime Dynamics Theory, Elitzur $(1991,1996)$ suggested that passage of an expanding universe creates space-time. Furthermore, "consciousness is the inner expression of the 'becoming' that keeps creating the universe one moment after another" (Elitzur, 1996, p. 149). In Ellis's (2014) evolving-block universe, the physical increase in cosmological events is referred to as the FOT when in effect he is referring to passage the same way Elitzur $(1991,1996)$ did. Huggett (2014) suggested that there is no percept of passage; what we really experience is change, 
duration, and motion. He also said that it is therefore unnecessary to incorporate physics into dynamic passage of time.

The term becoming is usually used in a manner like the term passage. Prigogine's (1980) approach to uncertainty in chaos theory also insisted that "events are becoming," and therefore the flow of time is not illusory. Dowker (2014) equated becoming with passage. She reviewed another new but very exciting type of evolving universe within Causal Set Theory (CST; Sorkin, 2007). Put simply, space is not smooth and continuous. It is made up of individual atoms (actually, spacetime atoms). They expand and grow in number but there is no space between them. The analogy is in chemistry with atoms comprising the solid that we experience. CST contains the concept of passage as the coming into being or birth of atoms of spacetime (featureless with no internal structure). However, being is a property of the past and once a space atom is born it is part of the past. Dowker noted that what is missing within the standard block universe view is the occurrence of the event (i.e., there is nothing corresponding to the "event happens" - a perceptual sense of the cosmological passage). The CST, on the other hand, provides that missing link by "breathing life into the standard block's static view" (p. 22). To be clear, passage, like motion, is not part of the standard block universe of Special Relativity. It is also not part of general relativity. For a basic explanation of time and space in general relativity, see Greene (2005) and Gruber et al. (1988). If the resulting experiential phenomenon of happening correlates with the birth of spacetime atoms within it, the experience itself according to CST must be an illusion: "Neurology, psychology ... must be responsible (will account) for this illusion" (Dowker, 2014, p. 24). Huggett (2014) agreed for the most part, and we chose to take that responsibility upon ourselves. Moreover, to simplify the situation, we find it best to view passage and becoming as the same or a similar phenomenon - a phenomenological coming-into-existence of events. We define passage as a phenomenon associated with the becoming of events at the cosmological horizon in a growing or evolving universe. The growth or evolution of the universe may be physical or psychological or both. In contradistinction, we define flow as (a) the percept of movement or change, and (b) the past/present/ future phenomenon (the cognition that objects and self-move from present to past). We will avoid the term becoming, and reserve the term happening for a newly introduced percept (see later).

\subsection{Duration, Duration Judgment, and Temporality}

Other terms are frequently associated with the FOT such as the experience (temporal order) associated with the succession of events (Block \& Patterson, 1994) and also duration. Husserl's exemplified duration as follows: "When one perceives a ball move in a trajectory, one never sees the ball as frozen in successive spatial positions. Rather, one always sees it as moving in a spatially extended trajectory over a certain time. In this case, the perceptual object is always presented as 
enduring or persisting and experienced as motion. Furthermore, the experience of duration is acquired for even fixed and stable objects (see Almang, 2013).

When quantified by the observer, duration becomes duration judgment, a quantitative measure of duration. For a review of duration judgment, see Block (1979, 2003), Block and Grondin (2014), Block and Zakay (1997), and Block et al. (2018). Thus, when a ball is thrown into the air the thrower needs to know and does know it is no illusion where the ball is to a good approximation in terms of the course the ball takes with respect to other objects (i.e., the temporal order of spatial changes and the duration judgment between those IGUS's spatial changes). Referring to it as a passage of time, Wittmann et al. (2010) demonstrated that duration judgment (measured by a reproductive task) involved the insula of the brain. To be clear, the standard (Einstein) block universe theory does not deny duration judgment or the temporal order of events - only the passage (becoming) and the flow (happening).

In the controversial Penrose and Hameroff (2011) Orch OR theory, consciousness is the creation of and the temporal sequence of quantum events (moments). We suggest that the components (both internal and external) of these resulting cerebral events (moments) are in no way illusory. The sequence of events (in memory) and resulting temporal order are also real information for the observer. We acknowledge that some do not view duration as a simple summation of a succession of (present) moments. For example, Kummel (1966, p. 33) suggested that duration is that perceptual phenomenon of time that is "free from all content" (other events or moments) and yet provides an enduring experiential quality. We argue that it is nearly impossible to avoid content. There are almost always ambient sounds, and the self-perception of breathing and other bodily movements. Even isolation chambers have difficulty achieving complete sensory deprivation. Finally, for the sake of completion, we note that temporality is a perceptual prerequisite for duration judgment. It is a before/after experience that makes it possible to experience duration and duration judgment. Temporality correlates with the physical succession or successivity of events, and Ruhnau (1997) reviewed it in detail.

\subsection{Illusions}

Much of the confusion within the topic of the FOT relates to the meaning of the word illusion, which was reviewed by Anstis (2009), Gregory (1991), and Zakay and Bentwich (1997). What is an illusion? This word is almost as stubborn and difficult as the word 'time'. By using the term illusion, we mean the more common usage whereby a perceptual phenomenon reported by a human observer conflicts with the physical measurements of what is observed. Specifically, it conflicts with the universally accepted physics of the situation. For example, the enigma illusion by Leviant (1996) is one of static concentric circles that when viewed by an observer appear to rotate. Although illusions may involve the senses (referred 
to as physiological or perceptual illusion) they may also involve cognition only. An example of the latter is the Kanisza (1976) triangle, which is referred to as a cognitive illusion.

Of many illusions, a class is functional by filling the gap. On the one hand, the perceived image filling the blind spot (Bach, 2014a) of the retina is clearly an illusory percept because the brain is not physically capable of recording information from that region. On the other hand, the fabricated image does usually agree with the local physical situation and is predictive and functional for the observer. Because so much of the world the observer is exposed to is fabricated by perceptual completion, Noe (2002; see also Blackmore et al., 1995) referred to the totality of these illusory percepts as the grand illusion. He noted that because more potential information exists than the brain can acquire, it is much more efficient for the brain to reconstruct the visual world from less information. It should be mentioned that theorists have debated as to whether there is, in fact, actual filling in and whether the brain simply ignores the blind spot and other regions (Blackmore et al., 2002; Bridgeman, 2002; Clark, 2002; Cohen, 2002; Dennett, 2002; Mack, 2002; Ramachandran, 1992). For a demonstration of the blind spot phenomenon, see Bach (2014a). A complete review of these perceptual completions, which are both static and dynamic, is given elsewhere (Pessoa \& De Weerd, 2003).

\subsection{Deconstructing the FOT}

Much confusion is avoided if we deconstruct the term or expression, FOT (Gruber et al., 2015). To clarify the meaning of it, Gibson (1975) argued that "a sequence of external stimuli ... provide[s] a flow of change, and it is this we perceive (experience) rather than a flow of time as such" (p. 299). He added that "the observer perceives both what is altered and what remains unaltered in the environment" (p. 298). To be clear, the FOT as defined here involves an experiential, perceptual phenomenon. Park (1999) went further, suggesting that "discussions of time become more clear if one drops the word 'time' entirely and substitutes one of the words 'event' or 'change' " (p. 20). We agree. Thus, the FOT is really the FOE (flow of events). However, to use the term flow of events from this point on would only create confusion, because it would add yet another term. Therefore, we will continue to use the expression FOT with the understanding that our definition refers to the perceptual flow of events. We must also be careful not to confuse the near instantaneous perceptual events with events (of much longer duration) in the event segmentation theory (Radvansky \& Zacks, 2014; Tversky \& Zacks, 2013). That theory elucidates how perceptual systems spontaneously segment activity into internal events (that have a beginning and an end) as a means of anticipating upcoming information. Finally, we should also acknowledge that some authors, such as Prior (2009), have referred to events as changes, which is reasonable.

The importance of change in the understanding of time was originally discussed by Aristotle (see Coope, 2009). He considered time to be fundamentally 
linked to change and movement: "Not only do we measure change by time, but time by change, because they are defined by one another" (Coope, 2009, p.107). We add that every change involves an event, and every event involves a change. Kastner (2015) took a different tack with the term change. For her, changes are bought about by transfers of energy from emitting entities to absorbing entities and time is just the attribute by which we measure those changes; that is, "time and energy...are two sides of the same coin" (p. 175).

Hameroff (2003) said "consciousness creates time" (p. 390). Therefore, consciousness creates (internal) events. Whether these events are those that comprise passage [part or all of an expanding evolving universe as Elitzur $(1991,1996)$ and others have suggested] is another even more debatable issue, which we discuss later. Even the experiential phenomenon of duration for fixed and stable objects [referred to by Husserl, as Brough (1991) noted] depends on non-specific unavoidable events such as breathing and body movement. Furthermore, events not only influence perceived time (Liverence \& Scholl, 2012), they are fundamental to the phenomenon of duration judgment. For a review of timing and discussion of internal clocks, see Block (2003), Block and Grondin (2014), Block and Zakay (1997), and Block et al. (2018).

We previously reviewed our understanding of the FOT (Gruber et al., 2015), a phenomenon that was discussed in detail by Foundalis (2008), Hameroff (2003), and Penrose (1994). There are actually two levels to the FOT (Davies, 2004; Gruber \& Block, 2013). There is an upper-level component, the past/present/ future, which entails a moving present. Time moves like a river, and events disappear into the past. It is often simply referred to as passage (Ismael, 2016). When Einstein referred to the "stubborn illusion," he was really thinking of the upper level of the FOT. The upper-level FOT is to which Park (1971) referred when he said that passage (the time through which we pass) is a myth. It is a myth in his opinion, we suspect, because it is an incorrect thought process — what we would call a false cognition.

As for the apparent asymmetry of the upper-level FOT (e.g., events appearing to go from future to present to past), Foundalis (2008) reminded us that cosmological time asymmetry is indicated by the ever-increasing overall entropy of the universe, providing a physical arrow of time. However, although the asymmetry is physical, the directionality can be cognitive. The directionality of the asymmetry is dictated by memory because the brain stores events in the direction of past-topresent. That is why we do not remember the future.

There is also a lower-level component of the FOT, the experience of events flowing or happening, such as occurs when a volcano erupts. It involves visual, auditory, olfactory, and other sensory modalities. It is the dynamic flux-like character of Price (2011). It is often simply referred to as flow (Ismael, 2016). It is the "whooshy, zingy thing" of Savitt's (2002) passage of time. It seems to be Husserl's duration of events within James's (1890) specious present. It also seems to 
be Hameroff's (2003) "illusion of continuity" for discrete moments acquired by $\mathrm{ORCH} / \mathrm{OR}$ quantum reduction. To be clear, it takes more than a single almost instantaneous external event to result in an experiential phenomenon that has a prolonged dynamic quality. A singular brief percept does not endure long enough to evoke a percept of flow. However, a series of external events during the specious present will evoke that experience.

\subsection{The Lower-Level FOT}

\subsubsection{Perceptual Completion of Apparent Movement and Motion}

The lower-level FOT (or passage of time, for some) is, in effect, the perceptual completion that provides continuity to discrete observation. Psychologists and neuroscientists have hinted that much of perception (particularly visual perception) is an illusion because the brain exhibits perceptual completion. These are illusory percepts to connect the experience of perceptual events which fill the gaps (Moore et al., 1998; Pessoa \& De Weerd, 2003; Wokke et al., 2013). One example is apparent movement (reviewed by Ramachandran \& Anstis, 1986), which is not often but sometimes discussed in terms of perceptual completion (Yantis \& Takehiko, 1998). For example, if one visual dot is followed in time by another further away, they seem like separate dots, separate in time. But if they are close in distance and time, the brain connects the two events by making the one dot appear to move back and forth. In this illusion, known as beta movement (important for motion pictures), the brain fills the gap and perceives a movement sensation. A similar type of illusory perceptual connection is the phi phenomenon (seen at interstimulus intervals greater than those associated with beta) in which a sensation of motion is experienced between the images of consecutive stimuli without a change their spatial position (Steinman et al., 2000).

If all visual perception is discrete the interval (gap) must be filled with an illusory percept. In fact, convincing evidence suggests that all perception may be discrete (intermittent), not continuous (VanRullen \& Koch, 2003;VanRullen et al., 2007). That is very apparent for the visual modality if not the auditory modality, in which discrete perception is expected to be discovered soon (VanRullen et al., 2014). If that is the case, all the sensory modalities of perceptual completion to fill the gaps need to be analyzed to appreciate how the lower-level FOT occurs and why those modalities are illusory. The evidence for motion comes largely from the continuous wagon wheel illusion (Andrews \& Purves, 2005; Crick \& Koch, 2007; Macdonald et al., 2014; VanRullen et al., 2010). Almost any observer perceives this when watching a wagon wheel in an old Western movie (or the wheel of a modern car) to roll forwards and then inexplicably roll backwards (for a visual demonstration, see Bach, 2014b). This wagon-wheel illusion occurs because the brain discretely samples the external world at approximately 10-13 times per second. As the rotation rate increases to a critical sampling value a point is reached such that the images of the wheel appear to move backwards (a phenomenon known 
as aliasing). The most parsimonious explanation is that perception is discrete, not continuous. It should be noted, however, that not all theorists agree that the wagon wheel experiment suggests discrete sampling (Kline \& Eagleman, 2008). However, despite those objections the resultant experiential visual result is that of a smoother more seamless picture than would occur otherwise (Holcombe, 2014).

Koch (2004) suggested that the percept of motion in the wagon wheel experiment may be "painted onto" the snapshots of visual perception. Such a paintingon process would, in effect, be yet another example of perceptual completion. It also appears to be an example of a superimposed percept or a quale, like that of music. Moreover, it is evoked in postdiction fashion, as has been described to occur for the flash lag illusion (Eagleman \& Sejnowski (2000). Using an inconsistent model of motion, Mortensen (2013) provided a schema to explain the experiential phenomena between snapshots of perception. Gruber and Block (2014) discussed some experiments that illustrate illusory perception between "snapshots" of stimuli. VanRullen (personal communication) considered the principle of bridging the gap (with motion) between 'snapshots' in discrete sampling of all motion scenes to be the same or like that in apparent movement. These views as to the illusory nature of motion are in good agreement with philosophical views. Paul (2010) argued that, in general, the flow associated with motion (a change of location of a persisting object) is merely an effect of the brain. Hoerl (2014) also argued that the passage of time (as he liked to refer to it) does not exist but is best explained by the experiences of movement and change.

The most recent evidence that perception is discrete comes from the study of Herzog et al. (2016). They provided a two-stage information processing model to account for discrete perception and also consciousness. They suggested that like other features, temporal features (such as duration) are coded as quantitative labels. When unconscious processing is completed, all features are simultaneously rendered conscious at discrete moments in time, sometimes even hundreds of milliseconds after stimuli were presented. Their model challenges prominent theories on the philosophy of mind, which considers that consciousness is a continuous stream. However, they acknowledged that the phenomenal experience of events has the appearance of continuity.

\subsubsection{Perceptual Completion of Dynamic Change}

Another example of a perceptual completion that comprises the lower-level FOT is dynamic change (Rensick, 2002). Nakashima and Yokosawa (2012) demonstrated it using a flicker change detection task. A 250-ms duration image of a bed oriented to the right was alternated with another oriented to the left with black blank interstimulus intervals (ISIs) between them varying from 100 to $2000 \mathrm{~ms}$. Participants were asked to give their impression of seeing the change occur. As the ISI increased, that impression weakened and was lost after $1000 \mathrm{~ms}$. Because the experience of change that the participants reported occurred during the black 
intervals, the researchers considered that the dynamic change experienced is an illusory one. Similarly, Hollingworth (2008) demonstrated perceptual completion in a flicker paradigm in which an initial object and a different object were shown for 250-ms duration and a blank ISI varying from 200 to $5000 \mathrm{~ms}$. Participants reported a strong impression of "seeing the change occur" at $200 \mathrm{~ms}$, a weaker impression at $1000 \mathrm{~ms}$, and no impression at $5000 \mathrm{~ms}$. Chen and Scholl (2016) performed a similar experiment in which the ISI was $17 \mathrm{~ms}$. The change appeared to be gradual even when it was actually sudden, in a type of transformational apparent movement.

\subsubsection{Perceptual Completion of the Percept of Happening}

We found another perceptual completion - a more generalized form of dynamic change (termed happening), one that crosses sensory modalities, is less dependent upon the qualitative nature of the stimuli, and one that extends for prolonged durations (up to ISIs of $7000 \mathrm{~ms}$ ). (For details, see Block \& Gruber, 2014; Gruber \& Block, 2013; Gruber et al., 2017.) Specifically, we tested for the illusory percept of perceptual completion for an entire sequence of stimuli rather than just two events (stimuli). For example, video scenes were created of a walking man. Ten (100-ms duration) images showed him walking for 50 feet. Black ISIs of 0.5, 3.0 or $7.0 \mathrm{~s}$ were inserted. Participants had to judge whether (a) the walk had 'happened' (i.e., that he had walked from one side to the other), or (b) the walk 'must have happened'. As the ISI increased, fewer participants experienced happening. At an ISI of $7.0 \mathrm{~s}$, very few participants experienced anything happening. Irrespective of the ISI the perceptual (qualitative) phenomenon of happening at $0.5 \mathrm{~s}$ did not appear to be any different than that at $3.0 \mathrm{~s}$ or even $7.0 \mathrm{~s}$ when it occurred. These results bear some relationship to Pöppel and Bao's (2014) findings. They noted that at $5 \mathrm{~s}$ two sequential stimuli can no longer be united into one percept (i.e., temporal binding for temporally adjacent stimuli is no longer possible because they fall into successive integration windows).

We also found a phenomenon of happening for a non-spatial (non-motion) sequence of stimuli - images of toasting bread. In this featural (color) change situation, 10 frames captured from toasting bread were used. Participants had to judge whether (a) they could see the toasting process, or (b) simply knew that it must have occurred. As the ISI was increased, fewer participants experienced that the process had happened. For an interactive demonstration, see Bach (2014c). Moreover, we found that to be the case with stimuli in other sensory modalities, both auditory (sequential sounds of a falling bomb) and tactile (a bug crawling up the forearm, with intermittent tactile contact; Block \& Gruber, 2014; Gruber et al., 2017). Irrespective of the sensory modality, happening appeared to be a frequency-dependent illusory percept. Technically speaking, it is more of a modal completion phenomenon. In dynamic situations, modal completion, in contrast to amodal completion, means that an observer's percept involves the same (sensory) 
mode, as if a contour were actually present. The best example of modal completion is the Kanizsa triangle, in which three Pacman-shaped figures provide the corners of a triangle yet evoke an illusion that a complete white triangle covers the disks comprising the Pacmen (Brodeur et al., 2006). This illusion is an example of reification - constructive perception by which the experienced percept contains more explicit information than the actual sensory stimulus. By contrast, amodal perception is the perception of the whole of a physical structure when only parts of it affect the sensory receptors (Singh, 2004). For example, a table will be perceived as a complete volumetric structure even if only part of it - the facing surface - projects to the retina.

Arguing on behalf of the illusory aspect of time flow, Prosser (2012) suggested that a key factor is that change is experienced as dynamic because the experience involves the representation of something enduring through the change. In the case of the happening experiments, it is reasonable to conclude, therefore, that the experience is much like what he describes. Finally, the perceptual completion of happening alone can fill the gap for all brief perceptual events (stimuli) in all sensory modalities. Thus, perceptual completion can account for the entire phenomenon of the lower-level FOT.

\subsubsection{Perceptual Completion in the Specious Present}

The responses to any series of stimuli, including intervening perceptual completion, that comprises an interval of 3-7 s, are part of the specious present (Block, 1979; Durgin \& Sternberg, 2002; Fairhall et al., 2014; Gruber, 2008; Kinsbourne \& Hicks, 1990; Pöppel, 1997; Ruhnau, 1997). The specious present is frequently referred to as the now, causing some confusion in definitions. We have even done that in the past (Gruber \& Block, 2013). Pockett (2003) reviewed the many different durations ascribed to the perceptual now - from $10 \mathrm{~ms}$ to several seconds and in extreme cases up to several hours. The duration can be quite different for philosophy in contrast to psychology. Whatever the duration is, it would be best to define now as the near instantaneous interval, and the longer interval of phenomenological duration (3-7 s in psychology) as the specious present. To be clear, we also note that the term moment is used interchangeably with the instantaneous now. As a reminder, the instantaneous perceptual now is not the same as the instantaneous physical now of SR and physics (Gruber \& Price, 1997; Hartle, 2005; Taylor \& Wheeler, 1992). Einstein had difficulty reconciling the now, as he called it. He was referring to the specious present. The reason it perplexed him is because it did not fit into his theory of relativity, making it potentially an incomplete theory (see Muller \& Maguire, 2016, p. 306). As we note later, however, if the brain (as observer) is part of the cosmological theory, there is no need to justify the specious present that is nicely explained by psychology.

During the specious present, the observer can work with the present moment and the memory of numerous prior present moments that occurred during that 
previous 3-7 s. Zahavi (2007) summarized the literature on the specious present. He noted that the present as it is experienced is not a pure point-like presence but has a width of several seconds and contains the past (memories) as what just happened. He referred to it as an extended moment consisting of a few seconds of memory. Within that interval of the stream of consciousness there is a distant component (the past end of it) and a less distant component (the present end of it). Expanding on this concept, Dalla Barba (2001) suggested there is a memory trace paradox, which consists in believing that the past is contained in the memory trace of the specious present (the now interval, as he called it). For him "objects...are neither present, nor past, nor future, but they acquire a temporal dimension only in the presence of a person who goes to the trouble of making them temporal" (p. 54). Montemayor and Wittmann (2014) proposed one of the most comprehensive approaches to this issue. They proposed a three-level present: (a) the experience of simultaneity (in the milliseconds range); (b) the experienced presence (referred to as the now) - a 2-3 s conscious experience of the present moment; and (c) the continuity of experience (requiring working memory) involving multiple seconds to generate a platform for the narrative self.

Noteworthy is the fact that the percept (modal completion) of happening (unlike other means of perceptual completion) can be evoked at ISIs up to 3-7 s. It is no coincidence that this duration coincides with that of the specious present. Thus, happening would seem to be much of the source of the dynamic flux-like quality (Price, 2011) of the specious present. Lastly, there is yet another possible illusory percept involving the specious present. It is the illusion of continuity between episodes of specious present. Pöppel (1997; Pöppel \& Bao, 2014) referred to them as states of being conscious (STUBCON) which are accompanied by the subjective feeling of nowness. Each STUBCON represents a mental island of activity distinctly separate from neighboring adjacent ones. He suggested that each island of nowness is implemented in a 3-s window and that the continuity of experience between islands is an illusion.

\subsubsection{The Lower-Level FOT is Backwards-in-Time}

Examples of the lower-level FOT entail a postdiction phenomenon, in which a stimulus influences the appearance of events occurring before it. In neuroscience, postdiction indicates that the brain includes information after an event in the process of retrospectively deciding what happened at the time of the event (Choi \& Scholl, 2006; Eagleman, 2008; Eagleman \& Sejnowski, 2000; Shimojo, 2014). A common example is the color phi phenomenon (Kolers \& von Grünau, 1976). A red disk is presented, followed by a green disk with a blank ISI between them. Remarkably, the observer experiences a continuous disk that changes colors halfway between the actual onset of the second disk. How does the observer know to perceive green before actually being presented with the green disk? Another example is the cutaneous rabbit illusion (Goldreich \& Tong, 2013). A person does 
not know that the touch on the wrist is going to be followed by a touch on the elbow. Yet he or she experiences something going up the forearm after the elbow is touched.

A major part of the lower-level FOT is exemplified by uncommonly known examples of postdiction phenomena. First and foremost is apparent movement. If the image of an object is located at point $x$, a person has no way of knowing that it will be at point $y 100 \mathrm{~ms}$ later. Therefore, it must reconstruct the scene in retrospect. The same is true for dynamic change. In the example of the rotating bed (see earlier), a person has no way of knowing that the second image of a bed is going to appear. Therefore, the change that is seen must be reconstructed in retrograde fashion. The same is true for the percept of happening. In the walkingman example described earlier, a person has no way of knowing that subsequent images of the man are going to appear. By conventional psychological theory, the experience of happening could not be acquired until the second image appeared. Furthermore, the modal completion of happening involves all sensory modalities. In combination with dynamic change and motion, it can easily account for every aspect of the lower-level FOT. All three of those percepts are backwards-in-time (postdiction) phenomena. Thus, the entire lower-level FOT is a backwards-intime phenomenon.

The mechanism by which postdiction can be accounted has not been fully explained. In terms of the underlying mechanisms, Arstila (2015) reviewed four prototypical models, which were called catchup, reentry, different pathway, and memory revision models. The latter model is one in which a tentatively established memory representation may be revised later (cf. Dennett \& Kinsbourne, 1992). However, in all these models the duration in which the postdiction phenomena occur is less than a few hundred milliseconds. Current mechanisms that justify those postdiction durations require correlations with known brain wave frequencies, such as alpha and theta in the $5-15 \mathrm{~Hz}$ range (Chakravarthi \& VanRullen, 2012). Those frequencies work well for postdiction intervals of approximately 50-150 ms. However, the happening postdiction phenomenon can be evoked at long ISIs (3,000-7,000 ms), making it difficult to account for postdiction at those long intervals.

\subsubsection{Alternative Views: Non-Phenomenology of Passage}

An alternative view of the lower-level FOT is that it is not a perceptual illusion. Hoerl (2014) argued that there is no phenomenology of passage (flow). Movement and change can explain how the brain comes to the belief (false cognition) that those experiences involve passage (flow). Baron et al. (2015) provided similar arguments. Their point is well made. We agree to the extent that flow is conflated with perceptual completion and add that time is conflated with events. However, we choose to focus on the nature of the perceptual experience associated with the FOT. Not all agree that it is an illusory percept. For example, Smolin (2013a; 2014; 
see Smolin \& Unger, 2015) has a Cosmological Natural Selection theory which involves a theory of Temporal Naturalism which declares that time as well as motion (personal communication) are real. To his credit and unlike other cosmological theorists he has offered two falsification experiments. Instead, we are suggesting that the cerebral experience of the lower-level FOT is based upon the illusory postdictive perceptual completion even if the brain conflates flow (passage) with perceptual completion. Thus, we think it is more important to demonstrate that the percepts of perceptual completion are all illusory. By extension this means motion, itself, is an illusory percept and, as such, contradicts Temporal Naturalism.

\subsection{The Upper-level FOT}

We are left with the need to find experiments that account for the apparent illusory phenomenon of the upper-level FOT, which involves cognition of past/ present/future. Consider what it means to view the world with events or objects moving into the past. Logically, it means that an object experienced now must be the same as when it was experienced then. It must persist. For a thorough review of the general phenomenon of the philosophy of persistence, see Haslanger and Kurtz (2006). This involves working memory processes. For example, a person thinks that he or she is the same person now as he or she was a few moments ago. For short interval situations (seconds) this is sometimes called object persistence (Scholl, 2007). But persistence also applies for long term situations (e.g., years.). Someone seems like the same person today as when he or she was younger. In many modern cosmologies, events and objects (including humans) persist within a block of space-time and have never disappeared. When Einstein's best friend Besso died, Einstein was consoled by the assumption that there is no past and present, no persistence as we would say, and therefore Besso was still there, so to speak (see Davies, 2002; Elitzur, 1996). In the block universe view, multiple different Bessos are in the past, and no single immutable Besso persists through time. If, therefore, an observer has a cognition that there is only one of him that persists he will, of necessity, have a cognition (the upper-level FOT) that he is moving into the past. Assuming that the Block Universe Theory is correct, it is a false cognition. This cognition of persistence seems to be inextricably linked to the past/present/ future phenomenon (the upper-level FOT). It allows us to think of persistence and the upper-level FOT as two sides of the same coin.

\subsubsection{Illusions and False Cognitions of Object Persistence}

Object persistence is a person's inclination to recognize an object as being the same despite a change in either its spatiotemporal situation or its features. When motion is hidden, such as in the classic tunnel effect (e.g., a car going through a tunnel), that type of perceptual continuity is maintained by amodal completion (Flombaum \& Scholl, 2006; Kim, et al., 2012; Michotte, 1991). In the tunnel effect, the observer has an experiential phenomenon in which the object that 
entered the tunnel (the occluder) did indeed pass through and exited as the same object. Moreover, even if the color of the exiting car is slightly different, the car that entered is cognitively the same car that exited. The automatic tendency of persistence is so overwhelming that the observer recognizes that somehow a minor change within the tunnel may have occurred. If, however, the exiting car is vastly different from the entering car, sameness (as it is often called) may not be evoked. Object persistence occurs because of the principle of spatiotemporal priority (Flombaum et al., 2009; Scholl \& Flombaum, 2010). Factors relating to how and where an object has moved will trump factors relating to what the object looks like, with few exceptions. However, surface features also play an important role in maintaining episodic object representations (Hollingworth \& Franconeri, 2009; Moore et al., 2010). To be clear, most of the time object persistence is incongruent with the physical facts, and it is a false cognition, not an illusion (i.e., not a problem with the sensation or perception).

Another example is the color phi phenomenon (see earlier). Not only is the color of the first disk seen to change colors during the interval between disks, but the disks are viewed as the same. Similarly, consider five different colored circular disks appearing sequentially from left to right on a viewing screen, with short time and distance intervals between them. At short ISIs, observers see one disk (the same disk) moving from one side to the other, changing colors as it appears to move. The brain does not register five different disks at five locations appearing at five separate times (Gruber \& Block, 2014).

As the ISI between the disks is increased, a duration is reached when the five disks appear to be all different, and there is no apparent movement between them. It is an example of a false cognition that is frequency- (ISI-)dependent. A more outrageous experimental example of the illusory potential of object persistence is a golf ball changing colors as it moves across the putting green. Even if it turns into a strawberry just as it falls into the hole, the golfer still considers it to be the same ball (his or her ball) that for unexplained reasons changed drastically. The brain does not consider the possibility that the ball disappeared and was replaced by a strawberry (Gruber \& Block, 2014). To be clear, a detailed analysis is required: After observing the strawberry to appear in place of the ball, there is a moment of cognitive reflection (however long that duration is in this situation). The result is an experiential phenomenon of object persistence between the recent memory of the ball (i.e., of the distant specious present) and the memory of the strawberry (i.e., of the less distant specious present). Without that experience of object persistence, the observer would perceive two unrelated objects.

Yet another example of the illusion of perceptual completion involves a binding cue: When color or motion momentarily exposes an object from a background of similar elements, observers remain aware of the object for a few seconds. For example, a bird camouflaged by leaves may not be seen. As it moves, the bird 
suddenly becomes visible. However, when it stops it is still visible for a short period of time (up to approximately $8 \mathrm{~s}$; Wong et al., 2009). That is a perceptual illusion, not a false cognition. It is associated with activation in the lateral occipital area. This visual persistence is not the same as iconic memory, which is of much briefer duration. Finally, Emrich et al. (2008) performed a similar experiment (a fragmented line-drawing moving relative to a background of randomly oriented lines) that demonstrated persistence of awareness at intervals up to $1500 \mathrm{~ms}$.

\subsubsection{Object Persistence in the Stationary (Non-Motion) Situation}

Object persistence occurs not only because of spatiotemporal priority (Mitroff \& Alvarez, 2007) but also, by extension, in temporal-only situations. Moore et al. (2010) exchanged the features of two objects abruptly and found that the object correspondence operation (persistence) could be established based on surfacefeature cues alone. Thus, a sudden change in the color of a stationary coin will evoke the perception of same, whereas a slow change (long ISI) in color will evoke the perception of different. The observer's brain entertains the possibility that the time interval was sufficiently long enough for change to occur. In general, therefore, we expect that the cognition of object persistence to be a time-dependent (and frequency-dependent) false cognition in the stationary situation.

The first compelling piece of evidence came from Beth and Ekroll (2015). A magician typically creates the illusion of transferring a coin from one hand into the other, which is then closed into a fist, while the coin is actually kept hidden in the first hand. The magical experience occurs when the closed fist of the second hand is opened and shown to be empty. The magical experience evoked by this kind of trick becomes noticeably weaker as the time interval between the false transfer and the opening of the fist increases. In this experiment, increasing the temporal interval from 1 to $32 \mathrm{~s}$ leads to an average reduction of the strength of the magical experience of $38 \%$. The researchers suggested that the experiential phenomenon that the coin was still there is an example of object persistence which decreases with time. They were careful to indicate that the experiential phenomenon might not be a percept per se and noted that Pylyshyn (1999) had raised the issue of the ambiguous nature of a percept. Mroczko-Wasowicz (2016) also questioned the close relationship between perception and cognition. We regard the authors' experimental finding as a phenomenon closer to a false cognition.

Beth and Ekroll's study prompted us to investigate the possibility that the brain has the potential to evoke perceptual completion for the intervals between discrete observations of a stationary object. This had not been done before but is logically possible. We used a phi-phenomenon experiment with two intermittently flashing disks of the same color (Gruber et al., 2016). When overlapped at short ISI intervals $(<100 \mathrm{~ms})$, they no longer flash but instead merge to appear as one disk - the same disk. The phenomenon may or may not be attributed to the type of visual persistence described by Wong et al. (2009). One can perform 
the experiment and adjust the variables by linking to Bach (2014d). ${ }^{1}$ Whatever the mechanism, the illusory perceptual completion leads to continuity and object persistence. The observer has no reason to invoke a cognition other than same. If the observer perceives objects discretely (intermittently), he or she could form a cognition of either same or different based upon other physical circumstances or theory; the cognition could go in either direction. However, perceptual completion for stationary objects prevents that from happening. Thus, the upper-level FOT results from a false cognition of object persistence attributable to illusory perceptual completion. Of note, any claim that the upper-level FOT is a false cognition must demonstrate that its evidence is independent of the cosmological facts or theories surrounding the upper-level FOT. None of those theories can be used to prove conclusively that the upper-level FOT is a false cognition or not. They can only predict it. As it turns out, the prediction by cosmological theories that it is a false cognition [or a myth as Park (1971), would say; or a mistake, as Huggett (2014) would say] are accurate according to the evidence we presented.

\subsection{Arguments Against Persistence as an Illusion or a False Cognition}

The notion that persistence, in general, could be an illusory or false cognition is contrary to the arguments of many (Haslanger \& Kurtz, 2006). Aristotle suggested that "a body which is carried along is the same body at each stage in its motion" (see Benjamin, 1966, p. 14). Both Dainton (2007) and Montemayor (2013) said that during the specious present one may be able directly to apprehend persistence or change. However, most modern philosophers think that the controversy on persistence is not whether it is an illusion or whether objects persist through change, but how they do so. Kurtz (2006) suggested that how persistence occurs depends upon what philosophical view one adopts (e.g., perdurance, endurance, or exdurance). For example, endurance theories (Van Inwagen, 1990) are intuitive. The same object is said to be present from moment to moment: "I am here now, and again at this new 'now'. I do not need to be thought of as extending into the past and future the way that I extend in space" (Scholl, 2007, p. 570). The perdurance view takes persistence to be a matter of having temporal parts, with no part being wholly present at more than one time and one place.

In Balashov's (2013) perdurance concept of persistence, it is more like an unchanging 'worm' in the space-time manifold, a composite of many different slices of spacetime events. He uses the classic ladder-in-the-barn paradox of Special

1 Set the disk duration to $10 \mathrm{~ms}$, the interdisk duration to $10 \mathrm{~ms}$, and the time of onset for the next pair of disks (called the preamble) to $0 \mathrm{~ms}$. As the disks are brought together and partially overlapped, they seem to flicker, but one will note an illusory percept shaped like a football during the interdisk interval. As the disks are completely overlapped, an illusory solid disk is seen. Perceptual completion provides a continuous color at these frequencies. The illusory overlap occurs at interdisk durations (ISIs) up to $60 \mathrm{~ms}$. 
Relativity (SR) to argue that the notion that a persisting object (one that 'perdures') can have a 'temporal part' is meaningless. We agree because so doing connotes an absolute quality when in fact length, duration and motion are relativistic measurements including the location of the aging process in the Twin Paradox (Price \& Gruber, 1996). Balashov acknowledged that whereas the spacetime worm perdures or persists, a space-time slice of that worm does not persist (personal communication, 2015). The observer experiences the slice as not the same at any two spacetime points. Furthermore, it cannot be numerically the same. Thus, there seems to be a possible place for perceptual completion in the theoretical framework of perdurance. To reach areas of agreement between philosophical and psychological views of persistence, Scholl (2007) analyzed both the neuroscience results and philosophical arguments of object persistence.

\section{Experiencing a World without the FOT}

To be more convincing that the entire lower-level FOT involves perceptual illusion of perceptual completion, it is essential to create a world without any FOT. Until now it has only been possible to provide a few examples in the visual modality and happening for a few modalities (auditory, haptic, or tactile, and visual). However, there are so many other perceptual phenomena such as the pressure from sitting, respiratory movement and verbal thinking that might involve perceptual completion. It would be ideal if we could control the frequency of all external and internal (self-stimulating) percepts or cognition and then test for perceptual completion. Our hypothesis begs an experiment in which the observer (participant) is exposed to a world of stimuli with a low frequency, such as an $\mathrm{Hz}<0.33$ (ISI $>3 \mathrm{~s}$ ), at which all of the modalities of perceptual completion that we have tested to date are not elicited. If all the other sensory modalities (e.g., buttock pressure from sitting, or respiration) are discrete and involve perceptual completion) perhaps their contribution to the lower-level FOT can be precluded by the same mechanism. One way to completely remove these percepts of dynamism is to allow intermittent short intervals of consciousness that are separated by long intervals of unconsciousness. If the long interval is greater than $3 \mathrm{~s}$, one would be bypassing the specious present.

We can only guess what intermittent consciousness might do to a participant. When the general anesthetic Methohexital (Brevital; see Ferrari \& Donlon, 1992) is employed (typically for short surgical procedures), retrograde amnesia results. Upon awakening (after 5-15 minutes of surgery) some patients (which the senior author has witnessed) offer their experience that they recall being told that they will be given the drug and the next thing they recall is becoming awake and told that the procedure is finished. Moreover, they are puzzled that "no time" elapsed between the two verbal events because they know that the procedure must have taken a finite amount of time. 
Coincidentally, Koubeissi et al. (2014) recently discovered that electrical stimulation of deeply implanted electrodes near the claustrum of an epilepsy patient results in a state of unconsciousness. Years earlier, Crick and Koch (2005) predicted that the claustrum is the so-called on-off switch for consciousness (Chau et al., 2015). The electrodes were placed there to eliminate the seizures. The claustrum is near the insula deep in the temporal cortex at a level near the top of the ear. Stimulation in this patient (for durations ranging from 3 to $10 \mathrm{~s}$ ) resulted in immediate loss of consciousness 10 out of 10 times, with cessation of reading, sudden blank staring, and unresponsiveness to visual or auditory commands. The patient returned to baseline as soon as the stimulation ceased, with no recollection of the events for the stimulation period. When stimulation at $14 \mathrm{~mA}$ was applied, the alteration of awareness occurred suddenly, within the first second.

Theoretically, intermittent claustrum stimulation appears to be an extraordinary method to test our hypothesis. To remove the role of perceptual completion, we first need to calculate the approximate ISI at which the happening percept is lost for that participant. That would be the off time. We assume that there are no perceptual completions of longer postdictive duration than that of the happening percept $(\sim 3 \mathrm{~s})$. The claustrum stimulus duration (on time) should be brief but needs to be the minimum required for appreciation of language (two adjacent words). A stimulus duration of about $500 \mathrm{~ms}$ is necessary for speech to be intelligible (Bashford et al., 1988).

What should we expect the claustrum participant to experience? If he or she is shown a video of a river with $3 \mathrm{~s} \mathrm{ISI,} \mathrm{we} \mathrm{expect} \mathrm{him} \mathrm{or} \mathrm{her} \mathrm{to} \mathrm{deny} \mathrm{experienc-}$ ing motion and, in fact, claim that the entire scene was static. He knows that the appearance of the river at the beginning is different than at the end. However, we expect he will acknowledge that he did not see anything happen. Of note, the error of conflation discussed by Hoerl (2014) and Baron et al. (2015) might still be there. The claustrum participant might have the belief that the passage of time was not experienced during the river scene. Of great importance from a physics perspective is that the claustrum experiment is a falsification test for the Temporal Naturalism theory of Smolin (2013a) that is so crucial to his cosmological theory (Smolin, 2014). Demonstrating that perceptual completion (including apparent movement and by extension, motion) is a mind-dependent percept makes it extraordinarily difficult to suggest that there is a second, independent motion of physical origin. Unfortunately, for our hypothetical experiment, the electrodes have been removed from the aforementioned patient. It may be some time before this fortuitous neurological situation is seen again.

\section{Summary}

We reviewed evidence from multidisciplinary research, including philosophy, physics, and psychological science. We clarified flow-and-passage time puzzles. 
We defined the terms (flow, passage, happening, becoming). Flow and passage are different, the former involving the psychological aspects of time and the latter involving the arguably evolving universe and associated cerebral events. We deconstructed the concept of the flow of time into two levels: (a) the lower level - a relatively automatic dynamic perceptual flux, happening, or flow of events (not time); and (b) the upper level - a relatively controlled cognitive view of past/present/future. The human brain conflates the expression flow of time (lower level) with the experiences of perceptual completion, and is therefore an illusory percept. It suggests a falsification experiment that resolves perceptual completion of the lower FOT. The claustrum (center of consciousness) might be intermittently stimulated to create a scenario of discrete observation with long interstimulus intervals of non-consciousness and thereby no perceptual completion. Evidence on the upper-level FOT reveals it as a false cognition that has the illusory percept of object persistence as its prerequisite.

\section{Acknowledgements}

We thank John W. Moore and two anonymous reviewers who suggested improvements and clarifications. We also thank Dave Karp, Access Video, and Jeff Lunzaga for suggesting the technology to complete many of our proposed experiments.

\section{References}

Almang, J. (2013). Axiomathes: Two kinds of time-consciousness and three kinds of content. Axiomathes, 23, 61-80.

Anderson, H. K., \& Grush, R. (2009). A brief history of time consciousness: Historical precursors to James and Husserl. J. Hist. Philos., 47, 277-307.

Andrews, T., \& Purves, D. (2005). The wagon-wheel illusion in continuous light. Trends Cogn. Sci., 9, $261-263$.

Anstis, S. M. (2009). Visual illusions. In T. Bayne, A. Coleremans, \& P. Wilken (Eds), Oxford companion to consciousness (pp. 363-367). New York, NY, USA: Oxford University Press.

Arstila, V. (2015). Keeping postdiction simple. Conscious. Cogn., 38, 205-216.

Arstila, V., \& Lloyd, D. (2014). Subjective time: The philosophy, psychology and neuroscience of temporality. Cambridge, MA, USA: MIT Press.

Bach, M (2014a). The blind spot. Retrieved January 30, 2015, from http://michaelbach.de/ot/cog blindSpot/index.html.

Bach, M. (2014b). Continuous light wagon wheel illusion. Retrieved January 30, 2015, from http:// michaelbach.de/ot/mot-wagonWheel/index.html.

Bach, M. (2014c). The toasting experiment. [Works best in Firefox with a full window]. Retrieved January 30, 2015, from http://michaelbach.de/ot/0_happening/capp/index.html.

Bach, M. (2014d). The color phi phenomenon. Retrieved January 30, 2015, from http://michaelbach .de/ot/col-colorPhi/index.html.

Balashov, Y. (2013). Persistence and spacetime. New York, NY, USA: Oxford University Press. 
Barbour, J. B. (1997). Nows are all we need. In H. Atmanspacher \& E. Ruhnau (Eds), Time, temporality, now (pp. 201-216). Berlin, Geremany: Springer Verlag.

Barbour, J. B. (2000). The end of time. New York, NY, USA: Oxford University Press.

Barbour, J. B. (2008). The nature of time. Retrieved March 21, 2017, from http://www.fqxi.org/data/ essaycontest-files/Barbour_The_Nature_of_Time.pdf?phpMyAdmin=0c371ccdae9b5ff3071bae $814 \mathrm{fb} 4 \mathrm{f} 9 \mathrm{e} 9$.

Barbour, J., Koslowski, T., \& Mercati, F. (2014). Identification of a gravitation arrow of time. Phys. Rev. Lett., 113, 181101.

Barnard, G. W. (2010). The ever-new flow of time: Henri Bergson's view of consciousness.J. Conscious. Stud., 17, 44-46.

Baron, S., Cusbert, J., Farr, M., Kon, M., \& Miller, K. (2015). Temporal experience, temporal passage and the cognitive sciences. Philos. Compass, 108, 560-571.

Bashford, J. A. Jr., Meyers, M. D., Brubaker, B. S., \& Warren, R. M. (1988). Illusory continuity of interrupted speech: Speech rate determines durational limits. J. Acoust. Soc. Am., 84, 1635-1638.

Benjamin, C. (1966). Ideas in time in the history of philosophy. In J. T. Fraser (Ed.), The voices of time (pp. 3-30). New York, NY, USA: Braziller.

Beth, T., \& Ekroll, V. (2015). The curious influence of timing on the magical experience evoked by conjuring tricks involving false transfer: Decay of amodal object permanence? Psychol. Res., 79, $513-522$.

Blackmore, S. (2002). There is no stream of consciousness. J. Conscious. Stud., 9, 17-28.

Blackmore, S. J., Brelstaff, G., Nelson, K., \& Troscianko, T. (1995). Is the richness of our visual world an illusion? Transsaccadic memory for complex scenes. Perception, 24, 1075-1081.

Block, R. A. (1979). Time and consciousness. In G. Underwood \& R. Stevens (Eds), Aspects of consciousness: Vol. 1. Psychological issues (pp. 179-217). London, UK: Academic Press.

Block, R. A. (1994). James, William (as psychologist) (1842-1910). In S. L. Macey (Ed.), Encyclopedia of time (pp. 320-321). New York, NY, USA: Garland.

Block, R. A. (2003). Psychological timing without a timer: The roles of attention and memory. In H. Helfrich (Ed.), Time and mind II: Information processing perspectives (pp. 41-59). Cambridge, MA, USA: Hogrefe and Huber.

Block, R. A., \& Grondin, S. (2014). Timing and time perception: A selective review and commentary on recent reviews. Front. Psychol., 5, 648. doi: 10.3389/fpsyg.2014.00648.

Block, R. A., \& Gruber, R. P. (2014). Time perception, attention and memory: A selective review. Acta Psychol. (Amst.), 149, 129-133.

Block, R. A., \& Patterson, R. (1994). Simultaneity, successiveness, and temporal-order judgments. In S. L. Macey (Ed.), Encyclopedia of time (pp. 555-557). New York, NY, USA: Garland.

Block, R. A., \& Zakay, D. (1997). Prospective and retrospective duration judgments: A meta-analytic review. Psychon. Bull. Rev., 4, 184-197.

Block, R. A., Grondin, S., \& Zakay, D. (2018). Prospective and retrospective timing processes: Theories, methods, and findings. In A. Vatakis, F. Balcı, M. Di Luca \& Á. Correa (Eds), Timing and Time Perception: Procedures, measures, and applications (pp. 32-51). Leiden, Netherlands: Brill.

Bridgeman, B. (2002). The grand illusion and petit illusions: Interactions of perception and sensory coding. J. Conscious. Stud., 9, 29-34.

Brodeur, M., Lepore, F. \& Debruille, J. B. (2006). The effect of interpolation and perceptual difficulty on the visual potentials evoked by illusory figures. Brain Res., 1068, 143-150.

Brough, J. B. (1991). On the phenomenology of the consciousness of internal time (1893-1917) (Husseriana: Edmund Husserl-Collected Works). Dordrecht, Netherlands: Kluwer Academic. 
Callender, C. (2010). Is time an illusion? Sci. Am., 302(6), 58-65.

Carroll, S. (2008). What if time really exists? Retrieved March 31, 2017, from http://fqxi.org/ community/forum/topic/318.

Chakravarthi, R., \& VanRullen, R. (2012). Conscious updating is a rhythmic process. Proc. Natl Acad. Sci. USA, 109, 10599-10604.

Chau, A., Salazar, A. M., Krueger, F., Cristofori, I., \& Grafman, J. (2015). The effect of claustrum lesions on human consciousness and recovery of function. Conscious. Cogn., 36, 256-264.

Chen, Y. C., \& Scholl, B. J. (2016). The perception of history. Psychol. Sci., 27, 923-930.

Choi, H., \& Scholl, B. J. (2006). Perceiving causality after the fact: Postdiction in temporal dynamics of causal perception. Perception, 35, 385-399.

Clark, A. (2002). Is seeing all it seems? Action, reason and the grand illusion. J. Conscious. Stud., 9, 181-202.

Cohen, J. (2002). The grand grand illusion. J. Conscious. Stud., 9, 141-157.

Coope, U. (2009). Time for Aristotle. Physics IV.10-14. Oxford, UK: Clarendon Press.

Crick, F. C., \& Koch, C. (2005). What is the function of the claustrum? Philos. Trans. R. Soc. Lond. B Biol. Sci., 360(1458), 1271-1279.

Crick, F., \& Koch, C. (2007). A neurobiological framework for consciousness. In M. Velmans \& S. Schneider (Eds), The Blackwell companion to consciousness (pp. 567-579). Malden, MA, USA: Blackwell.

Dainton, B. (2007). Coming together: The unity of consciousness experience. In M. Velmans \& S. Schneider (Eds), The Blackwell companion to consciousness (pp. 209-222). Malden, MA, USA: Blackwell.

Dainton, B. (2011). Time, passage, and immediate experience. In C. Callender (Ed.), The Oxford handbook of philosophy of time (pp. 382-419). Oxford, UK: Oxford University Press.

Dalla Barba, G. D. (2001). Beyond the memory-trace paradox past the fallacy of homunculus: A hypothesis concerning the relationship between memory, consciousness and temporality. J. Conscious. Stud., 8, 51-78.

Damasio, A. (1999). The feeling of what happens. New York, NY, USA: Harcourt Brace.

Davies, P. (2002). That mysterious flow. Sci. Am., 287(3), 40-47.

Davies, P. (2004). What is time? New York, NY, USA: Simon and Shuster.

Dennett, D. C. (2002). How could I be wrong? How wrong could I be? J. Conscious. Stud., 9, 13-16.

Dennett, D. C., \& Kinsbourne, M. (1992). Time and the observer. Behav. Brain Sci., 15, 183-201.

Dicks, D. (2016). Physical time and experienced time. In Y. Dolev \& M. Roubach (Eds), Cosmological and psychological time (pp. 3-20). New York, NY, USA: Springer.

Dowker, F. (2014). The birth of spacetime atoms as the passage of time. Ann. N. Y. Acad. Sci., 1326, $18-25$.

Durgin, F. H., \& Sternberg, S. (2002). The time of consciousness and vice-versa. Conscious. Cogn., 11, 284-290.

Eagleman, D. M. (2008). Prediction and postdiction: Two frameworks with the goal of delay compensation. Brain Behav. Sci., 31, 205-206.

Eagleman, D. M., \& Sejnowski, T. J. (2000). Motion integration and postdiction in visual awareness. Science, 287(5460), 2036-2038.

Elitzur, A. C. (1991). Consciousness and the passage of time: Two persistent wonders or one? Front. Perspect., 2, 27-33.

Elitzur, A. C. (1996). Time and consciousness: The uneasy bearing of relativity theory on the mindbody problem. In S. R. Hameroff, A. W. Kaszniak, \& A. C. Scott (Eds), Toward a science of consciousness (pp. 135-164). Cambridge, MA, USA: MIT Press. 
Ellis, G. F. R. (2008). On the flow of time: Essay for the Fqxi contest on the nature of time. Retrieved September 2, 2014, from http://arxiv.org/pdf/0812.0240.

Ellis, G. F. R. (2014). The evolving block universe and the meshing together of times. Ann. N. Y. Acad. Sci, 1326, 26-41.

Emrich, S. M., Ruppel, J. D. N., \& Ferber, S. (2008). The role of elaboration in the persistence of awareness for degraded objects. Conscious. Cogn., 17, 319-329.

Fairhall, S. L., Albi, A, \& Melcher, D. (2014). Temporal integration windows for naturalistic visual sequences. PLoS One, 9, 1-6.

Ferrari, L. R, \& Donlon, J. V. (1992). A comparison of propofol, midazolam, and methohexital for sedation during retrobulbar and peribulbar block.J. Clin. Anaesth., 4, 93-96.

Flombaum, J. I., \& Scholl, B. J. (2006). A temporal same-object advantage in the tunnel effect: Facilitated change detection for persisting objects. Journal of Experimental Psychology: Hum. Percept. Perform., 32, 840-853.

Flombaum, J. I., Scholl, B. J., \& Santos, L. R. (2009). Spatiotemporal priority as a fundamental principle of object persistence. In B. Hood, \& L. Santos (Eds), The origins of object knowledge (pp. 135-164). Oxford, UK: Oxford University Press.

Foundalis, H. E. (2008). Why does time 'flow' but space is? Answers in evolution and cognition, Essay for the Fqxi contest on the nature of time. Retrieved September 2, 2014, from http://fqxi.org/ community/forum/topic/276.

Gibson, J. J. (1975). Events are perceived but time is not. In J. T. Fraser \& N. Lawrence (Eds), The study of time II (pp. 295-301). New York, NY, USA: Springer Verlag.

Goldreich, D., \& Tong, J. (2013). Prediction, postdiction, and perceptual length contraction: A Bayesian low-speed prior captures the cutaneous rabbit and related illusions. Front. Psychol., 4, 1-26.

Greene, B. (2005). The fabric of the cosmos. New York, NY, USA: Vintage.

Gregory, R. L. (1991). Putting illusions in their place. Perception, 20, 1-4.

Grube, E. (2014). Atomism and the contents of experience.J. Conscious. Stud., 21, 13-33.

Gruber, R. P. (2008). Neurophysics of the flow of time. J. Mind Behav., 29, 239-254.

Gruber, R. P., \& Block, R. A. (2013). The flow of time as a perceptual illusion.J. Mind Behav., 24, 91-100.

Gruber, R. P. \& Block, R. A. (2014). The flow of time is an illusion (experiments to prove it). Fqxi physics video contest. Retrieved September 2, 2010, from http://fqxi.org/community/forum/ topic/2218.

Gruber, R. P., \& Price, R. H. (1997). Zero time dilation in an accelerating rocket. Am. J. Phys., 65, 979-980.

Gruber, R. P., Price, R., Matthews, S., Cordwell, W., \& Wagner, L. (1988). The impossibility of a simple derivation of the Schwarzchild metric. Am. J. Phys., 56, 256-269.

Gruber, R. P., Bach, M., \& Block, R. A. (2015). Perceiving two levels of the flow of time.J. Conscious. Stud., 22, 7-22.

Gruber, R. P., VanRullen, R., \& Block, R. A. (2016). Filling the gap for all stationary objects observed. Retrieved September 2, 2010, from https://youtu.be/yXqpLUUoJYc.

Gruber, R. P., Bach, M., \& Block, R. A. (2017). Dynamic perceptual completion of scenes (in different sensory modalities) as a result of modal completion. Am. J. Psychol.,130, 23-34.

Grush, R., \& Churchland, P. S. (1995). Gaps in Penrose's toilings. J. Conscious. Stud., 2, 11-29.

Hameroff, S. R. (2003). Time, consciousness and quantum events in fundamental spacetime geometry. In R. Buccheri, M. Saniga \& W. M. Stuckey (Eds), The nature of time: Physics, geometry and perception: Proceedings of a NATO Advanced Research Workshop, NATO Science Series II. Mathematics, Physics and Chemistry (Vol. 95, pp. 383-392). Amsterdam, Netherlands: Kluwer Academic. 
Hameroff, S. (2014). Consciousness, microtubules and “Orch OR”: A space-time odyssey.J. Conscious. Stud., 21, 126-153.

Hameroff, S. \& Penrose, R. (2003). Consciouss events as orchestrated space-time selectionos. NeuroQuantology, 1, 10-35.

Hameroff, S. \& Penrose, R. (2014). Consciousness in the universe: A review of the 'Orch OR' theory. Phys. Life Rev., 11, 39-78.

Hartle, J. B. (2005). The physics of now. Am. J. Phys., 73, 101-109.

Haslanger, S., \& Kurtz, R. M. (2006). Persistence: Contemporary readings. Cambridge, MA, USA: MIT Press.

Herzog, M. H., Kammer, T., \& Scharnowski, F. (2016). Time slices: What is the duration of a percept? PLoS Biol., 14, e1002433.

Hoerl, C. (2013). Time and the domain of consciousness. Ann. N. Y. Acad. Sci, 13326, 90-96.

Hoerl, C. (2014). Do we (seem to) perceive passage? Philos. Explor., 17, 188-202.

Holcombe, A. O. (2014). Are there cracks in the arcade of continuous visual experience? In V. Arstila \& D. Lloyd (Eds), Subjective time: The philosophy, psychology and neuroscience of temporality (pp. 179-198). Cambridge MA, USA: MIT Press.

Hollingworth, A. (2008). Visual memory for natural scenes. In S. J. Luck \& A. Hollingworth (Eds), Visual memory (pp. 137-162). Oxford, UK: Oxford University Press.

Hollingworth, A., \& Franconeri, S. L. (2009). Object correspondence across brief occlusion established on the basis of both spatiotemoral and surface feature cues. Cognition, 113, 150-166.

Huggett, N. (2014). Skeptical notes on a physics of passage. Ann. N. Y. Acad. Sci, 1326, 9-17.

Ismael, J. (2016). From physical time to human time. In Y. Dolev \& M. Roubach (Eds), Cosmological and psychological time. New York, NY, USA: Springer.

James, W. (1890). The principles of psychology. New York, NY, USA: Holt.

Kanizsa, G. (1976). Subjective contours. Sci. Am., 234(4), 155-163.

Kastner, R. E. (2015). Understand our unseen reality. London, UK: Imperial College Press.

Kim, S., Feldman, J., \& Sing, M. (2012). Curved apparent motion induced by amodal completion. Atten. Percept. Psychophys., 74, 350-364.

Kinsbourne, M., \& Hicks, R. E. (1990). The extended present: Evidence from time estimation by amnesics and normals. In V. Giuseppe \& T. Shallice (Eds), Neuropsychological impairments of short-term memory (pp. 319-330). New York, NY, USA: Cambridge University Press.

Kline, K. A., \& Eagleman, D. M. (2008). Evidence against the snapshot hypothesis of illusory motion reversal.J. Vis., $8,1-5$.

Koch, C. (2004). The quest for consciousness. Englewood, CO, USA: Roberts.

Koch, C., \& Hepp, K. (2006). Quantum mechanics in the brain. Nature, 440, 611-612.

Kolers, P. A., \& von Grünau, M. (1976). Shape and color in apparent motion. Vision Res., 16, 329-335.

Koubeissi, M. Z., Bartolomei, F., Beltagy, A. \& Picard, F. (2014). Electrical stimulation of a small brain area reversibly disrupts consciousness. Epilepsy Behav., 37, 32-35.

Kummel, F. (1966). Time as succession and the problem of duration. In J. T. Fraser (Ed.), The Voices of Time (pp. 31-55). New York, NU, USA: Braziller.

Kurtz, R. M. (2006). Introduction to persistence: What's the problem? In S. Haslanger \& R. M. Kurtz (Eds), Persistence: Contemporary readings (pp. 1-26). Cambridge, MA, USA: MIT Press.

Leviant, I. (1996). Does 'brain-power' make Enigma spin? Proc. R. Soc. Lond. B Biol. Sci., 263, 997-1001. Liverence, B. M. \& Scholl, B. J. (2012). Discrete events as units of perceived time.J. Exp. Psychol. Hum. Percept. Perform., 38, 549-554. 
Macdonald, J. S. P., Cavanagh, P., \& VanRullen, R. (2014). Attentional sampling of multiple wagon wheels. Atten. Percept. Psychophys., 76, 64-72.

Mack, A. (2002). Is the visual world a grand illusion? A response.J. Conscious. Stud., 9, 102-110.

Maudlin, T. (2007). The metaphysics within physics. Oxford, UK: Oxford University Press.

McTaggart, J. M. E. (2009). The unreality of time. In R. Le Poidevin \& M. MacBeath (Eds), The philosophy of time (pp. 23-34). Oxford, UK: Oxford University Press.

Michotte, A. (1991). Amodal completion of perceptual structures In G. Thines, A. Costall, \& G. Butterworth (Eds), Michotte's experimental phenomenology of perception (pp. 140-168). Hillsdale, NJ, USA: Erlbaum.

Mitroff, S. R., \& Alvarez, G. A. (2007). Space and time, not surface features, guide object persistence. Psychon. Bull. Rev., 14, 1199-1204.

Montemayor, C. (2013). Minding time: A philosophical and theoretical approach to the psychology of time. Boston, MA, USA: Brill.

Montemayor, C, \& Wittmann, M. (2014). The varieties of presence: Hierarchical levels of temporal integration. Timing Time Percept., 2, 325-338.

Moore, C. M., Yantis, S., \& Vaughan, B. (1998). Object-based visual selection: Evidence from perceptual completion. Psychol. Sci., 9, 104-110.

Moore, C. M., Stephens, T. \& Hein, E. (2010). Features, as well as space and time, guide object persistence. Psychon. Bull. Rev., 17, 731-736.

C. Mortensen (2013). Motion perception as inconsistent. Philos. Psychol., 26, 913-924.

Mroczko-Wasowicz, A. (2016). Perception-cognition interface and cross-modal experiences: Insights into unified consciousness. Front. Psychol., 7, 1592-1594.

Muller, R. A., \& Maguire, S. (2016). Now, and the flow of time. Retrieved September 2, 2017, from https://arxiv.org/pdf/1606.07975v1.pdf.

Nakashima, R., \& Yokosawa, K. (2012). Sustained attention can create an (illusory) experience of seeing dynamic change. Vis. Cogn., 20, 265-283.

Noe, A. (2002). Is the visual world a grand illusion? J. Conscious. Stud., 9, 1-12.

Nunez, P. L. (2010). Brain, mind and the structure of reality. New York, NY, USA: Oxford University Press.

Park, D. (1971). The myth of the passage of time. Stud. Gen. (Berl.), 24, 19-30.

Park, D. (1999). What is time? In M. Wegener (Ed.), Time creation and world order (pp. 15-22). Aarhus, Denmark: Aarhus University Press.

Paul, L. A. (2010). Temporal experience. J. Philos., 107, 333-359.

Penrose, R. (1994). Mechanisms, microtubules and the mind.J. Conscious. Stud., 1, 241-249.

Penrose, R., \& Hameroff, S. (2011). Consciousness in the universe: Neuroscience, quantum spacetime geometry and Orch OR theory. In R. Penrose, S. Hameroff, H. P. Stapp, \& D. Chopra (Eds), Consciousness and the universe: Quantum physics, evolution, brain and mind. Cambridge, MA, USA: Cosmology Science.

Pessoa, L., \& De Weerd, P. (2003). Filling in: From perceptual completion to cortical reorganization. New York, NY, USA: Oxford University Press.

Petkov, V. (2007). Relativity and dimensionality of the world. Dordrecht, Netherlands: Springer.

Pockett, S. (2003). How long is now? Phenomenology and the specious present. Phenomenol. Cogn. Sci., 2, 55-68.

Pöppel, E. (1997). The brain's way to create "newness." In H. Atmanspacher \& E. Ruhnau (Eds), Time, temporality, now (pp. 107-120). Berlin, Germany: Springer Verlag. 
Pöppel, E., \& Bao, Y. (2014). Temporal windows as a bridge from objective to subjective time. In V. Arstila \& D. Lloyd (Eds), Subjective time: The philosophy, psychology and neuroscience of temporality (pp. 241-261). Cambridge MA, USA: MIT Press.

Price, H. (2011). The flow of time. In C. Callender (Ed.), The Oxford handbook of the philosophy of time (pp. 276-311). Oxford, UK: Oxford University Press.

Price, R. H., \& Gruber, R. P. (1996). Paradoxical twins and their special relatives. Am. J. Phys., 64, 1006-1008.

Prigogine, I. (1980). From being to becoming: Time and complexity in the physical sciences. San Francisco, CA, USA: Freeman.

Prior, A. N. (2009). Changes in events and changes in things. In R. Le Poidevin \& M. MacBeath (Eds), The philosophy of time (pp. 35-59). Oxford, UK: Oxford University Press.

Prosser, S. (2012). Why does time seem to pass? Philos. Phenomenol. Res., 85, 92-116.

Pylyshyn, Z. (1999). Is vision continuous with cognition? The case for cognitive impenetrability of visual perception. Behav. Brain Sci., 22, 341-365.

Radvansky, G. A., \& Zacks, J. M. (2014). Event segmentation. New York, NY, USA: Oxford University Press.

Ramachandran, V. S. (1992). Filling in the blind spot. Nature, 356, 115.

Ramachandran, V. S., \& Anstis, S. M. (1986). The perception of apparent motion. Sci. Am., 254(6), 102-109.

Rensink, R. A. (2002). Change detection. Annu. Rev. Psychol, 53, 245-277.

Rickles, D., \& Kon, M. (2014). Interdisciplinary perspectives on the flow of time. Ann. N. Y. Acad. Sci., $1326,1-8$.

Ruhnau, E. (1997). The deconstruction of time and the emergence of temporality. In H. Atmanspacher \& E. Ruhnau (Eds), Time, temporality, now (pp. 53-70). Berlin, Germany: Springer-Verlag.

Savitt, S. (2002). On absolute becoming and the myth of passage. In C. Callender (Ed.), Time reality \& experience (pp. 153-167). Cambridge, UK: Cambridge University Press.

Scholl, B. J. (2007). Object persistence in philosophy and psychology. Mind Lang., 22, 563-591.

Scholl, B. J., \& Flombaum, J. I. (2010). Object persistence. In B. Goldstein (Ed.), Encyclopedia of perception (Vol. 2, pp. 653-657). Thousand Oaks, CA, USA: Sage.

Shimojo, S. (2014). Postdiction: Its implications on visual awareness, hindsight, and sense of agency. Front. Psychol., 5, 1-19.

Singh, M. (2004). Modal and amodal completion generate different shapes. Psychol. Sci., 15, 454-459.

Skow, B. (2011). Experience and the passage of time. Philos. Perspect., 25, 359-387.

Smolin, L. (1997). The life of the cosmos. New York, NY, USA: Oxford University Press.

Smolin, L. (2013a). Time reborn. New York, NY, USA: Houghton Mifflin Harcourt.

Smolin, L. (2013b). A perspective on the landscape problem. Found. Phys., 43, 21-45.

Smolin, L. (2014). Time, laws, and the future of cosmology. Phys. Today, 67, 38.

Smolin, L. \& Unger, R. M. (2015). The singular universe and the reality of time. Cambridge, UK: Cambridge University Press.

Sorkin, R. D. (2007). Relativity theory does not imply that the future already exists: A counterexample. In V. Petkov (Ed.), Relativity and the dimensionality of the world: Fundamental theories of physics. Chicago, IL, USA: Springer.

Steinman, R. M, Pizlo, Z., \& Pizlo, F. J. (2000). Phi is not beta. Vis. Res., 40, 2257-2264.

Taylor, E. F., \& Wheeler, J. A. (1992). Spacetime physics. New York, NY, USA: Freeman.

Tversky, B. \& Zacks, J. M. (2013). Event perception. In Reisberg, D. (Ed.), Handbook of cognitive psychology (pp. 83-94). New York, NY, USA: Oxford University Press. 
Van Inwagen, P. (1990). Four-dimensional objects. Nous, 24, 245-255.

VanRullen, R., \& Koch, C. (2003). Is perception discrete or continuous? Trends Cogn. Sci., 7, 207-213.

VanRullen, R., Carlson, T., \& Cavanaugh, P. (2007). The blinking spotlight of attention. Proc. Natl Acad. Sci. USA, 104, 19204-19209.

VanRullen, R., Reddy, L., \& Koch, C. (2010). A motion involved illusion reveals the temporally discrete nature of visual awareness. In R. Nihawan \& B. Khurana (Eds), Space and time in perception and action (pp. 521-535). New York, NY, USA: Cambridge University Press.

VanRullen, R., Zoefel, B., \& Ilhan, B. (2014). On the cyclic nature of perception in vision versus audition. Philos. Trans. R. Soc. Lond. B Biol. Sci., 369, 2013-2014.

Wearden, J. H. (2016). Passage of time judgements. Conscious. Cogn., 38, 165-171.

Whitrow, G. J. (1980). The natural philosophy of time. Oxford, UK: Clarendon Press.

Williams, D. C. (1951). The myth of passage.J. Philos., 48, 457-472.

Wittmann, M., Simmons, A. N., Aron, J., \& Paulus, M. P. (2010). Accumulation of neural activity in the posterior insula encodes the passage of time. Neuropsychologia, 48, 310-320.

Wokke, M. E., Vandenbroucke, A. R. E., Scholte, H. S., \& Lamme, V. A. F. (2013). Confuse your illusion: Feedback to early visual cortex contributes to perceptual completion. Psychol. Sci., 24, 63-71.

Wong, Y. J., Aldcroft, A. J., Large, M., Culham, J. C., \& Villis, T. (2009). The role of temporal synchrony as a binding cue: An fMRI study.J. Neurophysiol., 102, 3461-3468.

Yantis, S., \& Takehiko, N. (1998). Visual interactions in the path of apparent motion. Nat. Neurosci., $1,508-512$.

Zahavi, D. (2003). Husserl's phenomenology. Stanford, CA, USA: Stanford University Press.

Zahavi, D. (2007). Perception of duration presupposes duration of perception — or does it? Husserl and Dainton on time. Int. J. Philos. Stud., 15, 453-471.

Zakay, D., \& Bentwich, J. (1997). The tricks and traps of perceptual illusions. In M. S. Myslobodsky (Ed.), The mythomanias: The nature of deception and self-deception (pp. 73-103). Hillsdale, NJ, USA: Erlbaum. 